
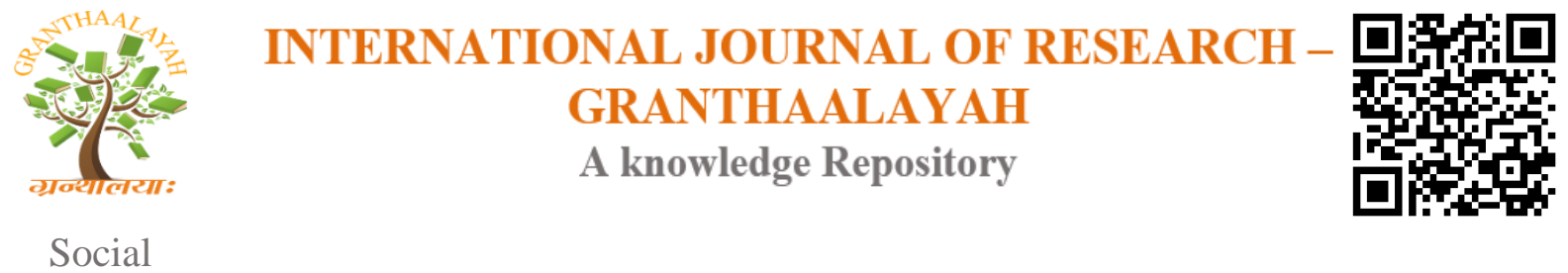

\title{
SUSTAINABILITY OF SCHOOL FEEDING PROGRAMME IN WESTERN ZAMBIA
}

\author{
Constance Sitali ${ }^{1}$, Oswell Chakulimba ${ }^{2}$, Sophie Kasonde- Ng'andu ${ }^{3}$ \\ ${ }^{1}$ Kwame Nkrumah University-Kabwe, Zambia \\ ${ }^{2,3}$ University of Zambia-Lusaka, Zambia
}

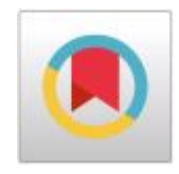

\begin{abstract}
School Feeding Programme (SFP) is the provision of food to primary day-school children. It is an intervention designed to support the education of children living in poverty and food insecure areas. It is viewed as a potential safety net and social support measure that help keep children in school and make them learn. The study was designed to establish the sustainability of school feeding programme in Zambia with specific focus on Western Zambia. A descriptive survey design was used. The study employed both qualitative and quantitative research methods. The instruments that were used in data collection included questionnaires, interviews and focus group discussion guides. This research was conducted in nine of the sixteen districts of Western Zambia. The sample consisted of four hundred fifteen respondents drawn from the targeted population. Simple sampling and purposive sampling procedures were used to select the respondents. Qualitative data were analysed using descriptive statistics while qualitative data were done using the thematic approach. The findings of the study revealed that SFP in most schools was not sustainable because it relied mostly on external support and also showed that the challenges faced the implementation of SFP were diverse. Few Schools that revealed SF was sustainable attributed the sustainability to the school projects they were engaged in. It was also disclosed that Home Grown School Feeding (HGSF) was identified as the best option for effective and sustainable SFP. The study recommends the need for the government to revamp the production unit in all the schools; for correct assessment of local and national capacity, and the need for complimentary investment in local agricultural production to ensure smooth programme operation and sustainability.
\end{abstract}

Keywords: School Feeding Programme; Sustainability; Home- Grown School Feeding.

Cite This Article: Constance Sitali, Oswell Chakulimba, and Sophie Kasonde- Ng'andu. (2020). "SUSTAINABILITY OF SCHOOL FEEDING PROGRAMME IN WESTERN ZAMBIA." International Journal of Research - Granthaalayah, 8(4), 340-351. https://doi.org/10.29121/granthaalayah.v8.i4.2020.73.

\section{Introduction}

The background to this study had its inspiration from various studies that highlighted the multiple benefits of school feeding programme (SFP) and the researcher was driven by the need to establish 
the sustainability of the programme. School Feeding Programme has existed in both developed and developing countries since the beginning of the nineteenth century (WFP, 2006). According to Sibanda (2012), as early as 1930's, school feeding programme was introduced in the United States of America and the United Kingdom to improve children's health. He further indicated that other countries like India and Brazil also introduced school feeding programme after the Second World War in 1945. It has a long history as a social protection tool. The provision of meals in schools was one of the first public welfare programme worldwide and among the first interventions to be widely delivered through the education sector. School Feeding is the supply of at least one nutritional meal at school on a daily basis to Primary day-School children attending classes (WFP, 2012). According to Tomlinson, M (2007) different countries have one or both of the feeding modalities; on site school feeding and take home ration. The concept of in-school meals implies the provision of food to learners in school while take-home ration is amount of food given to learners to take home to share with their families. The benefit of the food provided under the school feeding programme is conditional on the attendance of the learner on that specific day. It is an intervention designed to support the education of children living in poverty and food insecurity areas.

Hunger is a barrier to learning and school feeding programme throughout the world has successfully addressed this hindrance and subsequently attracted children to school. Studies so far carried out in most countries indicated that School Feeding Programme is one of the effective interventions to enhance the challenges of low school enrolment, attendance and poor academic performance among others (UNICEF 2005).

The concept of the school feeding programme in developing countries like Zambia was generally aimed at improving the quality of learning through improved enrolment, attendance and academic performance to the poor (Bundy et al, 2009). Studies undertaken show multiple benefits of school feeding. The empirical evidence on educational outcomes shows that School Feeding meets a set of educational goals that include increased enrolment, more consistent attendance, a lower dropout rate, and improved school performance (Ahamed, 2004). The School feeding programme can help to get children into school and help to keep them there, through enhancing enrolment and reducing absenteeism and once the children are in school, the programme can contribute to their learning through avoiding hunger and enhancing cognitive abilities. The use of school feeding programme in developing nations like Zambia is clearly a critical intervention that should be considered and sustained. However, a significant challenge to this programme was in the uncertainty of its sustainability; despite the multiple benefits of school feeding programme little was known about how the programme was going to be continued in an event of donor exit. Furthermore, it was well known that most of the School Feeding Programme in low-income countries relied mostly on external funding, which then poses a potential threat to the sustainability of this programme and this created a gap. Therefore, this study intended to establish the sustainability of School Feeding Programme even in the absence of the external support in Zambia with specific focus on Western Zambia as the area of study.

\section{Materials and Methods}

The study employed a descriptive survey design to establish sustainability of school feeding programme in Western Zambia. Descriptive survey design was chosen to allow the researcher to 
gather information, summarize, present and interpret data for the purpose of clarification. The study used both the quantitative and qualitative research methods. The targeted population for the study were head teachers, teachers, learners from selected primary schools benefiting from school feeding programme in Western Zambia; District Education Planners, World Food Programme (WFP) Provincial Coordinator and parents of learners from participating schools were also included in this study. The sample consisted of four hundred fifteen respondents drawn from the targeted population. Simple sampling and purposive sampling procedures were used to select the respondents. Advantages of using simple random sampling are that the samples yield research data can be generalized to a larger population. Also permits the researcher to apply inferential statistics to the data and provides equal opportunity of selection for each element of the population while in purposive sampling, the goal was to select cases that were likely to be 'information rich' with respect to the purpose of the study. Questionnaires, Focused Group Discussions and Interview Guides were used to collect the data for the study. Reliability and Validity of the Instruments are vital concepts in all investigations. Validity of research instrument were viewed and evaluated by the researcher with the help of supervisors. This was done to determine if the instruments were measuring what they intended to measure. To enhance the reliability of instrument used in the study, researcher assured that all interviews were conducted in a consistent manner and a pilot study was conducted before the main research. Suggestions concerning instructions, clarity of questions and relevance among others from the pilot test were considered and this made it possible to make amendments where necessary to suit the intended purpose.

Questionnaires were administered to WFP provincial coordinator, District Education planners, head teachers and teachers; Focused group discussions were conducted with learners, Interviews were conducted with parents to supplement information gathered by questionnaires and seek clarification on emerging issues. Quantitative data were analysed using descriptive statistics such as frequencies and percentages while qualitative data were coded and analysed using thematic approach.

Permission to conduct the study was obtained from the Ethical Committee of the University of Zambia and also from the Provincial Education Office in Western Zambia. Consent was also sought from all the nine District Education Board offices and participants. Confidentiality and anonymity was ensured at all stages of data collection.

\section{Presentation of Findings}

The presentation of the findings was in relation to the set objective; to establish the sustainability of school feeding programme in Western Zambia. To achieve the research objective, quantitative and qualitative methods were used.

\subsection{Sustainability of School Feeding Programme}

To establish whether or not school feeding programme was sustainable, 415 respondents (WFP Provincial Coordinator, Head teachers, Teachers, planners, parents, and learners) were asked to give their opinion. The results are presented in table 1. 
Table 1: Responses on whether or not SFP is sustainable

\begin{tabular}{|l|c|c|}
\hline Responses & Frequency & Percentage \\
\hline Yes & 48 & 11.6 \\
No & 363 & 87.4 \\
Not sure & 4 & 1.0 \\
\hline Total & 415 & $100 \%$ \\
\hline
\end{tabular}

The study findings showed that out of the 415 respondents, $48(11.6 \%)$ indicated that school feeding programme was sustainable. On the other hand $363(87.4 \%)$ of the respondents indicated that it was not sustainable and $4(1 \%)$ respondents were not sure whether or not School Feeding Programme was sustainable.

The respondents $(11.6 \%)$ who indicated that school feeding programme was sustainable based their argument on the following factors: From WFP perspective, School Feeding Programme was not stand alone project but part of the main stream operation of United Nations global programmes where it was drawing much of its resources. The WFP Provincial Coordinator highlighted the issue of partnership and this is what was stated:

There are partners such as Concern Worldwide who supports local production of cowpeas to promote rural household income through the $\mathrm{P} 4 \mathrm{P}$ local purchase programme in some districts and also UNICEF which deals with school health and nutrition and home-grown school feeding programme.

It was also stated that Home Grown School Feeding (HGSF) which is a nationally owned programme was identified as one of the mechanisms by World food programme in partnership with local governments and communities. It was further explained that WFP had started the integrated project management; where, small scale farmers were supported to grow crops like cowpeas, beans and other produce relevant to school feeding.

The Coordinator further highlighted the following:

- In Zambia, the government is meeting about three quarters $(3 / 4)$ of the implementation costs through the provision of bulky maize grain and meeting the secondary transportation costs to schools and many other hidden operational costs. WFP covers the cost of other inputs such as oil and pulses.

Other respondents indicated that school feeding was sustainable because they did not rely totally on external support. One head teacher stated:

- Apart from what we receive from the World Food Programme and the government, the school has fish ponds and vegetable gardens from which we are able to supplement the running of the School Feeding Programme activities. Refer Figure 1 and 2 


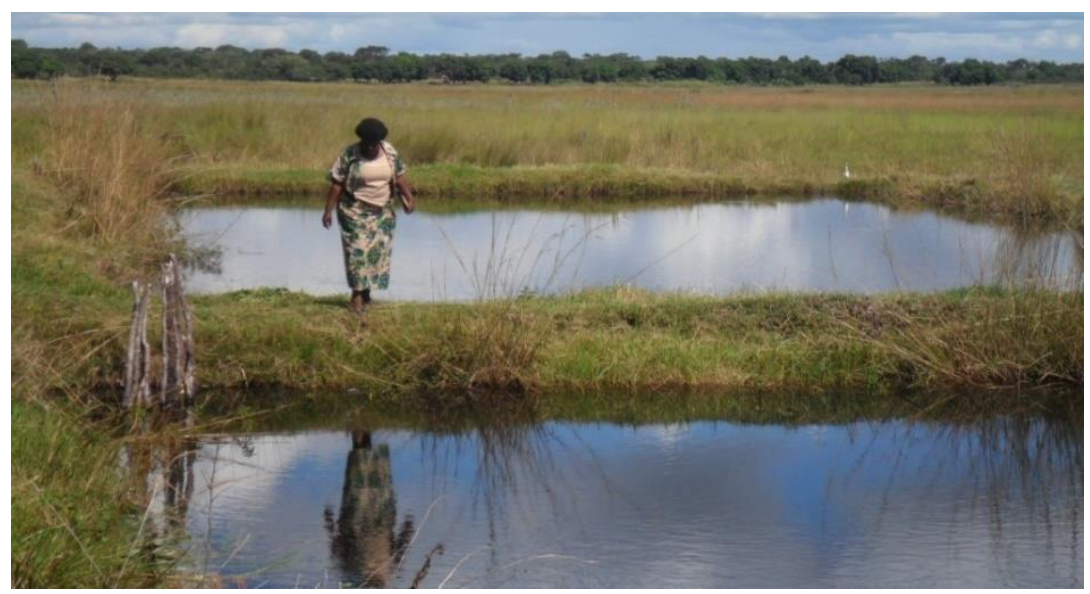

Figure 1: Fishponds at Mawawa Primary School, Mongu District

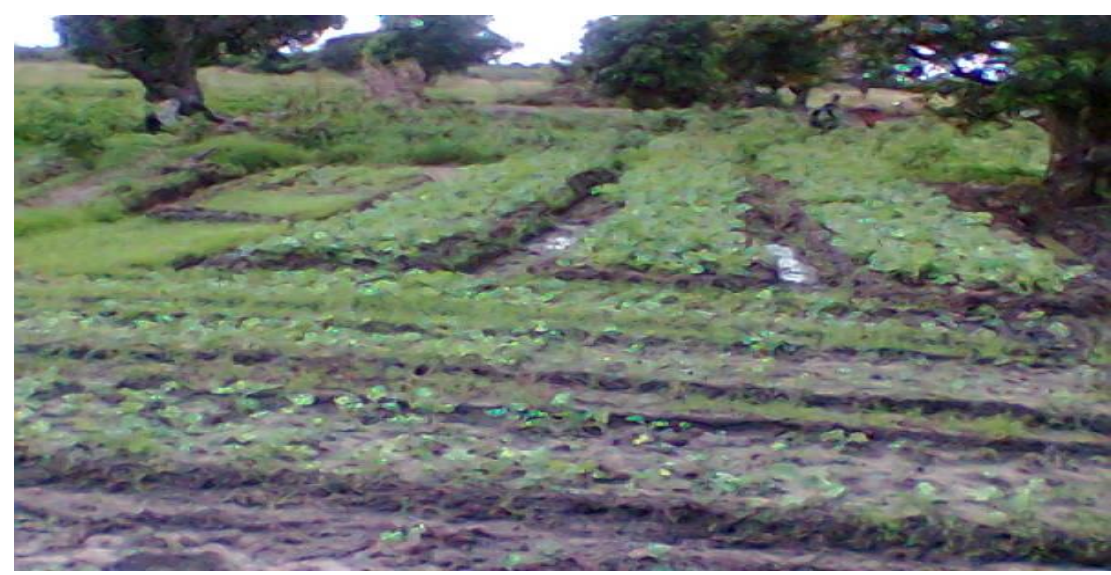

Figure 2: Vegetable garden at Mawawa Primary School, Mongu District

Another head teacher indicated that at their school they kept animals such as pigs that they could sell as a whole or slaughter to supplement external school feeding foods that were sometimes not supplied like salt and sugar. Refer Fig 3

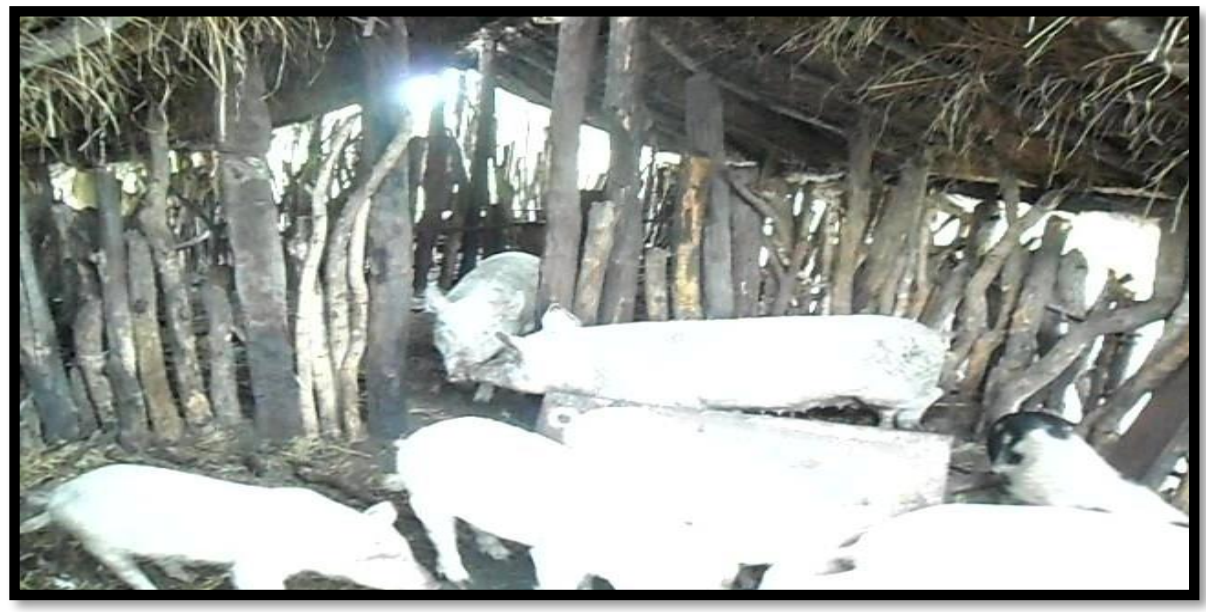

Figure 3: Pig rearing at Maondo Primary School, Sesheke District. 
In addition, Teachers also explained that most schools especially in rural areas had enough land where some were already engaged in productive agriculture activities. Equally, other teachers further indicated that, some schools had ventured into alternative farming activities such as keeping pigs, goats, chickens that were helping to enhance the sustainability of school feeding programme.

Similarly, district Planners indicated that SFP was sustainable because capacity building trainings were conducted and the focal point persons were trained in food management, general reporting, general government tender and procurement procedures. It was further revealed that at some point schools were trained to equip their members in agriculture techniques. This is what one of the district planners stated:

- To ensure that school feeding programme is sustainable, teachers were trained in agriculture techniques to improve and increase their production in their school gardens throughout the year, which many schools adopted. Such schools find fewer challenges even in situations when food supplies were not delivered on time, because they have backup supplementary stocks to continue providing meals to their learners.

In one of the focus group discussions learners disclosed that instead of depending much on beans supplied by the donor, learners also had vegetables and fish from their school garden and fish ponds. From the interviews with parents, it became clear that school feeding programme was sustainable. This is what was said by one parent:

- This is based on the fact that, the government is contributing much more hidden cost to the running of the programme, the government provide; storage facilities, volunteer teachers coordinating the activities at school level, labour and transport of food stuff and other logistics.

For those respondents (87.4\%) who indicated that school feeding programme was not sustainable, when asked to justify their responses, some stated the dependency syndrome; that the programme mostly depended on the external support. This was emphasised by one of the head teachers as he was pointing to what was written on the food packaging. "... because even the food stuff packaging is written and marked with the World Food Programme logo."

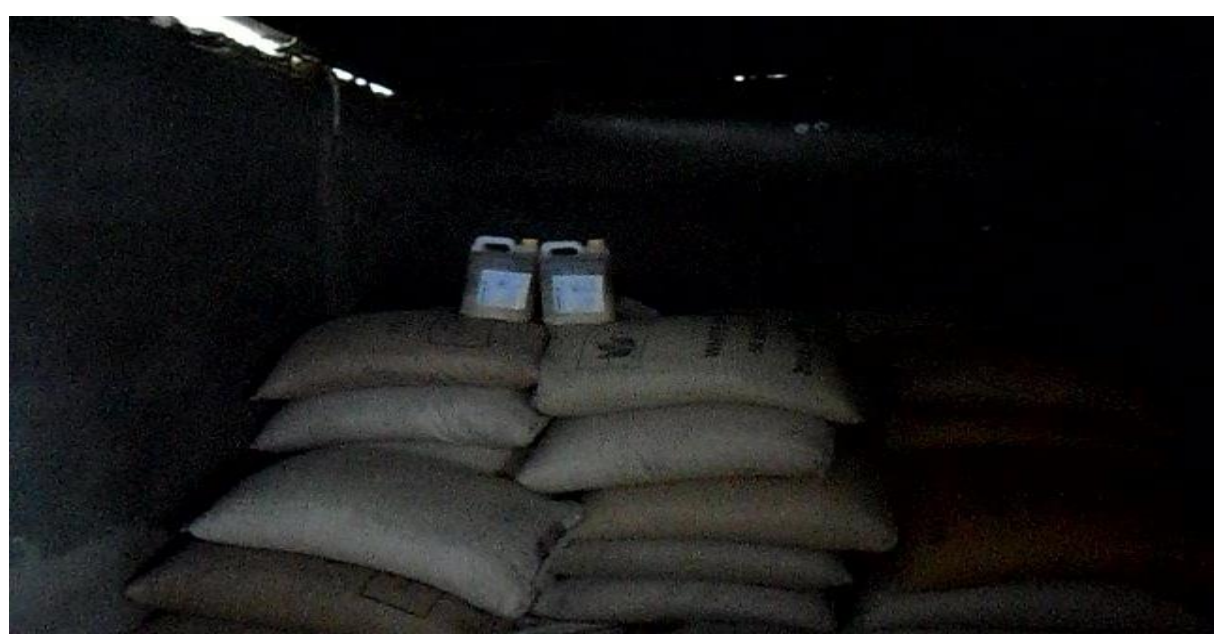

Figure 4: Food items with WFP Logo 
The Head teachers also revealed that there was an inconsistency in the delivery of food to schools by the government and that sometimes the schools had to run without food for the whole term.

In relation to the same research question, one teacher had this to say:

- Since there is no clear policy by government to guide the implementation of the school feeding programme, this has made the government not answerable to any shortfalls in resources to run the programme.

This was validated by the absence of any budget allocation to the programme in the national budget and if external donors were to pull out, that was going to be the end of the programme.

Since the removal of user fees, and no substantial help coming in from government to supplement schools, most schools are finding it difficult to carry out certain school activities, including school feeding. In this state, it is impossible to imagine how an expensive programme like school feeding could be sustained without external support.

Planners on the same question noted that most communities were passive actors in the implementation of the school feeding programme apart from minor assistance in form of preparing food and collecting firewood. It was further stated that if the programme was to be sustainable then measures were needed to be taken to tap from huge resource base lying idle in many communities.

Some parents also added their views:

- Sometimes food can be in schools, but cannot be prepared [sic] due to a number of challenges such as; poor cooking shelters, distance to water sources, fire wood, cooking utensils, schools unable to provide funds for grinding maize meal, as the programme has no such allocation in its operation costs.

Parents felt that if these and other teething challenges were not addressed, then the sustainability of the programme shall remain questionable.

In addition, one parent had this to say:

- Purchasing food from us small holder farmers for school feeding cannot sustain the programme because of an unpredictable weather changes such as floods and droughts; also the high cost of farming inputs and late distribution of farm inputs results in poor yields.

The learners in their discussion groups also registered their views on why they felt the programme was not sustainable. One group member said:

- Ahaa! [sic] Sometimes we usually take long or even a term would pass without school meals, because food has not been delivered.

Further, another group member had this to say:

- During the rainy season we rarely have daily school meals because most of our schools have no better cooking shelters, parents fail to come to prepare meals, fire wood not collected, or owners of cooking utensils have refused to give them to school. 


\section{Discussion of the Findings}

\subsection{Sustainability of School Feeding Programme}

The core of this research question was to establish whether or not school feeding programme was sustainable. Two contrary views surfaced from the research findings. The majority of the respondents indicated that School Feeding Programme was not sustainable, while minority of the respondents felt the programme was sustainable.

The minority of the respondents who indicated that school feeding programme was sustainable attributed the sustainability to the fact that the programme was not a stand- alone project but part of the main stream operation of United Nations global programmes where it was drawing much of its resources. This was similar to WFP (2002) when stated that for WFP to achieve its mandate, it partners with governments, UN agencies, non-governmental organisations (NGOs), community organisations, and the private sector companies for funding and other support particularly in lowincome countries. One other significant issue Gelli, A (2010) observed was the fact that in its role as a global leader in SF, and in line with its policy WFP is committed to working with partners to analyse and share knowledge to better support governments in implementing sustainable national programme. This showed that WFP had embarked on a number of initiatives to ensure resources are mobilized for the sustenance of the programme. The bringing in of national governments, local communities and business groups partnership would help to mop up local resources that may bridge the gap.

It is undisputable that school feeding programme has enormous accrued benefits both to the learners and the entire community. Therefore, to safe guard these benefits; stakeholders are in pursuit of diversity mechanisms that will drive the programme for time to come. In view of this, respondents mentioned Home Grown School Feeding (HGSF) among others as a sustainable measure to ensure the sustainability of the programme. Respondents' views showed that the SFP was sustained when schools purchased their food from local farmers or produced their own foods from school production units.This finding was in line with the views of WFP(2013) that the sustainability of school feeding is enhanced through the inclusion of a number of small-scale farmers in food deficit areas through the HGSF approach, which was aimed at hunger and poverty reduction. This was also in conformity with the approval of Sumberg and Sabates-Wheeler, (2011) who approved that the innovative element of HGSF is in supporting smallholder farmers to enable them to gain access to a predictable and stable local market and school feeding programme that is linked to local agricultural production can create structured and predictable markets for local and smallholder produce. Home-grown school feeding has the potential to transform local communities, both economically and socially by involving several groups within the community in the programme. This may encourage investments in improved food production and quality, leading to improved income, food security and resilience for farmers as Espejo etal (2009) postulates that smallholder' farms are the backbone of agriculture in low and middle income countries.

For every programme to succeed, the key persons needed to have knowledge and skills in the particular field hence, capacity building trainings were conducted and focal point persons were trained. It was also noted that there were partners such as Concern Worldwide who supported local 
production of cowpeas to promote rural household income through the purchase for progress (P4P) and also UNICEF which dealt with school health and nutrition and also home grown school feeding. This finding was supported by Masset E and Gelli A (2011) who stated that the relationships with governments from the national to the local level is key to successful school feeding programme and there is a tendency to favour local purchase of food which support local smallholder farmers as well as reduce costs.

Other respondents indicated that SFP was sustainable because they did not rely totally on external support; some schools had fishponds and vegetable gardens from which they were able to supplement the running of the School Feeding. This was fitting well with what Masset E and Gelli A (2011) advocated for; local purchase of food being cheap. If gardening is to have a real long-term effect on children's diets, then nutritional needs must provide the overall rationale for garden activities, governing decisions about what to plant and what to do with the produce.

The respondents who indicated that school feeding was not sustainable noted the inconsistency in the delivery of food to schools by the government or failure by individual schools to organise logistics to collect food from central storage facilities, which sometimes has led to schools run without food for the whole school term. The same emphasis was alluded to by Tomlinson (2007) who had indicated that the programme faced some challenges, such as poor coverage and high costs and inconsistencies in meal provision amongst others. This was also the position of Bundy et al (2009) who stated that Sustainability of the school feeding programme in low and middle income countries is still a big challenge because of the inability to produce enough food, frequent rise of food prices affecting household food access,

Respondents also indicated that school feeding programme was not sustainable because it depended on external support. This observation concurs well with that of Andrews et al (2011) who noted that most school feeding programme in the developing countries is donor funded, through the World Food Programme, faith-based organizations like Catholic Relief Services, or other development organisations, such as CARE, Bill and Melinda Gates Foundation, Save the Children among others. School feeding has been based on food aid which is not sustainable and just like most foreign aid do come with some conditionality. The very fact that the current operation of the programme was totally dependent on external donors contribution, meaning any drop in resource flow from the donors, will automatically mean a shift in the way the programme is implemented. This has been seen when schools have failed to offer meals to learners, reason being that WFP has not delivered food to the Ministry or food has come towards the end of the school term.

Most of the respondents were of the view that the programme was not sustainable because of the low level of agricultural technology and high dependency on rainfall for farming activities. This coupled with unpredictable weather changes such as floods, droughts and also high cost of farming inputs and late distribution of government farm input support programme result in poor yields, subsequently affect the implementation of school feeding negatively.

Some of the studies suggested other strategies that might bring school feedings' sustainability in low- income countries. The suggested alternatives to sustainable school feeding programme includes the establishment of school gardens (Najumba, 2013), the community based school 
feeding programme (Andrews, Colin et al., 2011), the home-grown school feeding programme (Sumberg and sabates - Wheeler,2011) and involvement of the private sectors in the school feeding programme (Bundy et al., 2009). Though studies suggested the alternative school feeding programmes as ways to run the school feeding programme without over dependence on donors, still they do not adequately address the question of how the programme, for example, be run in case of changes of weather, level and quality of food production.

Even if local communities and schools were to get into farming, the effect of climate change, could still affect the yields, making the programme unable to meet its obligation of providing sufficient food to learners.

\section{Conclusion}

The concept of school feeding programme in low-income countries like Zambia was generally aimed at improving school enrolment, attendance, performance and to provide social protection to the poor. The core of this study was to establish the sustainability of school feeding programme in Western Zambia. Based on the findings of the study, two contrary views surfaced; The majority of the respondents indicated that SFP was not sustainable, whilst the minority felt the programme was sustainable. Despite the different views, Home Grown School Feeding (HGSF) was identified as one of the mechanisms to ensure the sustainability of the programme. The rationale behind HGSF based on the use of locally-produced food is that it can provide a regular market opportunity and a reliable source of income for smallholder farmers. HGSF has a double effect in that it targets both small scale farmers and school-aged children. Moreover, home-grown school feeding if well designed, has the potential to transform local communities, both economically and socially, by involving several groups within the community in the programme. Therefore, HGSF can contribute to improving rural livelihoods and reducing poverty, while supporting school feeding programme to become sustainable.

\subsection{Theoretical Implications of Findings}

The sustainability of school feeding programme was derived by the fact that the current leading sponsor, WFP will not run the programme endlessly and that the learners will still need food for schooling. The intension was therefore to establish the sustainability of the school feeding programme after the donor exit and best approach to make the programme sustainable and beneficial to the school children.Based on the theoretical, the programme evolves depending on the specific context and capacities of the different stakeholders involved. In this study, policy framework, financial capacity and community participation were adopted as one of the key issues to sustain School Feeding Programme.

Political will and government's commitment provide creative solutions for a guaranteed long lasting feeding programme by developing clear policies that enforce the effective implementation of the feeding programme. A policy basis for a SFP helps strengthen its potential to ensure sustainability and the quality of implementation. The availability of funds; whether from the government, private institutions or donor organisations is also one of the factors to ensure sustainability of SFP. Stable funding is a basic requirement to run a School Feeding Programme. As the programme becomes a national programme, it needs to have a stable funding source independent of external support. Community participation is a concept that attempts to bring 
different stakeholders together for problem solving and decision making. School feeding programme which responds to community needs is locally owned, and which incorporate some form of community contribution. Involving community is a way to ensure that the benefits brought by a development programme would be maintained after the external interventions exit. Community participation is necessary for social mobilization and for growing community ownership.

\section{Recommendations}

The researcher made recommendations based on the findings.

- The study recommends the need for the government to revamp the production unit in all the schools; for correct assessment of local and national capacity, and the need for complimentary investment in local agricultural production to ensure smooth programme operation and sustainability.

- To protect and foster the safety net benefits associated with Home Grown School Feeding, the Government of Zambia needs to increase the production capabilities of rural farmers by improving irrigation systems and farming technologies. This can be achieved through the Ministry of Agriculture providing more support in the form of rural farming grants, accessible inputs and indigenous plant knowledge.

- Need for the Ministry of Agriculture to work together in a coordinated manner under the inter-ministerial committee on social affairs for planning, setting goals and achieving concrete activities in benefit of small-scale farmers in the diversity production.

\section{References}

[1] Ahmed, A.U. (2004). Impact of Feeding Children in School: Evidence from Bangladesh, International Food Policy Research institute (IFPR) Washington, DC: Mimeo.

[2] Bundy, D., Burbano, C., Grosh, M., Gelli, A., Jukes, M. and Drake, L. (2009). Rethinking School Feeding: Social safety nets, child development and the education sector, Washington, DC: World Bank.

[3] Colin, Andrews. (2011). Social safety Nets in Fragile states: A Community-Based School Feeding Programme, Social protection and labour. Togo: The World Bank.

[4] Espejo, F., Burbano C., \&Galliano, E. (2009). Home-grown School Feeding: A Framework to Link School Feeding with Local Agricultural Production. Rome: World Food Programme

[5] Gelli, A. (2010). Food Provision in Schools in Low- and Middle-income Countries: Developing an Evidence Based Programme Framework. Working Paper. London: Partnership for Child Development.

[6] Masset E., Gelli, A. (2011). Community Participation and the Links Between Agriculture, Nutrition and Education Design of a Randomised Field Experiment of 'Home-grown' School Feeding in Mali PCD Working Paper London: PCD.

[7] Najumba, I. (2013). Improving Learning In Uganda, Volume I: Community-Led School Feeding Practices and Issues for consideration. Washington: World Bank Publications.

[8] Sibanda, D. G. (2012). An Investigation into the Implementation of the School Supplementary Feeding Programme in Windhoek, Namibia. Windhoek: University of Namibia.

[9] Sumberg, J. \& Sabates-Wheeler, R. 2011. Linking agricultural development to school feeding in sub-Saharan Africa: Theoretical Perspective Food Policy.

[10] Tomlinson, M. (2007). Soverenity School feeding in East and South Africa: Improving food, Health systems. Research unit. Medical Research Council. 
[11] UNICEF (2005) The State of the World's Children Report. Excluded and Invisible. Newyork: UNICEF.

[12] WFP, (2006) Global School Feeding Report, Rome; WFP

[13] WFP (2003) Global School Feeding Report, WFP-Rome, April.

[14] WFP 2010. Home Grown School Feeding: A Framework to Link School Feeding with Agricultural Production. Rome: WFP

[15] WFP Centre of excellence against Hunger (2012). Annual Report 2012. Brasilia: WFP

[16] WFP (2013). State of the Feeding Worldwide 2013, Rome: WFP.

*Corresponding author.

E-mail address: sitaliconnie@gmail.com 